GEOPHYSICAL RESEARCH LETTERS, VOL. 13, NO. 6, PAGES 597-600, JUNE 1986

\title{
SOURCE CHARACTERISTICS OF THE 1985 MICHOACAN, MEXICO EARTHQUAKE AT PERIODS OF 1 TO 30 SECONDS
}

\author{
Heidi Houston and Hiroo Kanamori
}

Seismological Laboratory, California Institute of Technology, Pasadena, CA 91125

\begin{abstract}
Source characteristics of the Sept. 19, 1985 Michoacan, Mexico earthquake and its aftershock on Sept. 21 were inferred from broadband and short-period teleseismic GDSN records. We Fourier-transformed the $P$ waves, corrected for instrument response, attenuation, geometrical spreading, and radiation pattern (including the depth phases), and then averaged to obtain the teleseismic source spectrum from 1 to $30 \mathrm{~s}$. The Michoacan source spectrum is enriched at $30 \mathrm{~s}$ and depleted at 1 to $10 \mathrm{~s}$ relative to an average source spectrum of large interplate subduction events. Source spectra for the Sept. 21 aftershock, 1981 Playa Azul, 1979 Petatlan, and 1978 Oaxaca events follow a trend similar to that of the 1985 Michoacan event. This spectral trend may characterize the Mexican subduction zone.
\end{abstract}

A station-by-station least-squares inversion of the Michoacan earthquake records for the source time function yielded three source pulses, which we interpreted as events on the fault plane. The first two are similar in moment, and the third contains only $20 \%$ of the moment of the first. Directivity is evident in the timing. At each station, we measured the time differences between the pulses, and performed a least-squares nonlinear estimation of the strike, distance, and time separation between the events to locate them relative to one another. The second event occurred 26 s after the first, and $82 \mathrm{~km}$ southeast of it, indicating southeastward rupture along the trench. The third event occuired $21 \mathrm{~s}$ after the second, and about $40 \mathrm{~km}$ seaward of it. The two large events are also seen in the near-field strong motions.

The mainshock records, spectrum, and time functions contain less high frequency radiation than those of the $1985 \mathrm{Val}-$ paraiso, Chile earthquake. Apparently, the Michoacan earthquake ruptured two relatively smooth, strong patches which generated large $30 \mathrm{~s}$ waves, but small 1 to $10 \mathrm{~s}$ waves. Such behavior contrasts with the Valparaiso event which had a more complex rupture process and generated more 1 to $5 \mathrm{~s}$ energy. This difference is consistent with the higher nearfield accelerations recorded for the Valparaiso event.

\section{Introduction}

On September 19, 1985 a large subduction earthquake $\left(\mathrm{M}_{W}\right.$ $=8.0$ or 8.1 ) occurred in the Michoacan gap along the Mexican trench (see. Figure 1). It had the largest seismic moment of any earthquake in 1985. Unusually high accelerations in Mexico City caused heavy damage and thousands of deaths. From an earthquake engineering point of view, it is important to distinguish between the source effects of this earthquake and site or propagation effects peculiar to Mexico City. To this end, we analyzed teleseismic broadband and short-period GDSN (Global Digital Seismic Network) records of the Sept. 19 earthquake and its Sept. 21 aftershock $\left(M_{W}\right.$ $=7.6$ ) to determine their source characteristics at periods of 1 to $30 \mathrm{~s}$. We compared their source spectra to those of other

Copyright 1986 by the American Geophysical Union.

Paper number 6L6083.

$0094-8276 / 86 / 006 \mathrm{~L}-6083 \$ 03.00$ recent Mexican subduction earthquakes which were digitally recorded. GDSN records are also available for the March 3, 1985 Valparaiso, Chile earthquake $\left(\mathrm{M}_{\mathrm{W}}=8.0\right)$ along the Chile trench, the second largest earthquake in 1985. We will show that the Michoacan earthquake source has a long duration (about 1 minute), but is depleted in energy at 1 to $10 \mathrm{~s}$ periods relative to an average source of that size and relative to the Valparaiso earthquake, suggesting that the unusually high accelerations in Mexico City were not a source effect. This conclusion is consistent with a comparison of the nearfield strong motion data for the two events. Teleseismic data, therefore, can be used to predict some characteristics of near-field strong motions.

\section{GDSN Records and Spectral Analysis}

Figure 2 shows some of the broadband and short-period vertical records available for the Sept. 19 and Sept. 21 events. Two distinct source events about $25 \mathrm{~s}$ apart are clearly visible on the broadband records of the mainshock.

We performed a spectral analysis of the available records, using the procedure described in. Houston and Kanamori [1986]. We windowed, tapered, and Fourier-transformed the $\mathrm{P}$-wave train to obtain the displacement spectrum, $\hat{u}(\omega)$. The end of the window was chosen where the amplitude dropped to about $25 \%$ of the maximum amplitude or before the phase $\mathrm{PP}$ arrived, whichever happened first. The moment rate spectrum (moment rate spectral density) $\hat{\mathrm{M}}(\omega)$; for each earthquake is given by:

$$
\hat{\mathrm{M}}(\omega)=\frac{4 \pi \rho \alpha^{3} R_{\mathrm{E}}}{\mathrm{g}(\Delta) \mathrm{R}_{\theta \phi} \mathrm{C}}\left[\frac{\mathrm{e}^{\frac{\omega t^{*}}{2}} \hat{\mathrm{I}}(\omega)}{\mathrm{u}}(\omega)\right]
$$

where $\rho$ and $\alpha$ are the density and $\mathrm{P}$-wave velocity at the source, $R_{E}$ is the radius of the earth, $g(\Delta)$ represents geometrical spreading, $\mathrm{R}_{\theta \phi}$ is the eflective radiation pattern of the $\mathrm{P}$-wave train that includes the $\mathrm{P}, \mathrm{pP}$, and $\mathrm{s}$ phases, $\mathrm{C}$ is the free-surface receiver effect, $t^{*}$ represents attenuation, and $\hat{\mathrm{I}}(\omega)$ is the instrument response.

In all the events studied here, the crust is involved in faulting. Hence, we took $\rho=2.8 \mathrm{gm} / \mathrm{cm}^{3}$ and $\alpha=6.5 \mathrm{~km} / \mathrm{s}$. For $\mathrm{t}^{*}$ we used $0.7 \mathrm{~s}$. The effective radiation pattern and free-surface receiver effect, $R_{\theta \phi}$ and $C$, were computed from the station distance and azimuth and the focal mechanism of the event; we used fault strike $\phi=-72^{\circ}$, dip $\delta=9^{\circ}$, and rake $\lambda=72^{\circ}$ for both the mainshock and the aftershock [Eissler et al., this issue]. $\mathbf{R}_{\theta \phi}$ is obtained by first computing the amplitudes of the $\mathrm{P}, \mathrm{pP}$; and $\mathrm{sP}$ phases at the station, and then taking the root-mean-square value. Actually, the depth phases will interfere to yield a frequency-dependent radiation pattern. But the frequency-dependence is small in an average sense, especially for extended ruptures [Houston and Kanamori, 1986].

The moment rate spectra obtained for each record are then averaged. Figure 3 shows the average moment rate spectra for the Michoacan mainshock and the Sept. 21 aftershock, and the 1981 Playa Azul, 1979 Petatlan, 1978 Oaxaca, and 


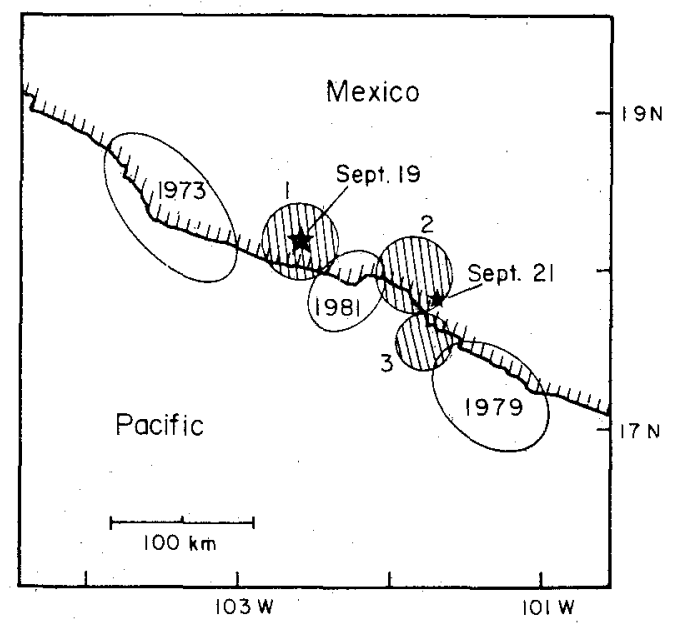

Fig. 1. Map view of the 1985 Michoacan, Mexico earthquake rupture zone. Stars show the PDE epicenters of the mainshock and largest aftershock. The shaded areas show the inferred rupture zones of the three source sub-events of the mainshock found by this study, assuming a rupture velocity of $2.5 \mathrm{~km} / \mathrm{s}$ and sub-event rise times of $10 \mathrm{~s}, 10 \mathrm{~s}$, and 7 s. Rupture zones inferred from aftershock areas of the 1973 , 1979, and 1981 earthquakes are also shown.

1985 Valparaiso, Chile earthquakes. All of the above earthquakes, except the last, occurred along the Mexican subduction zone. The Petatlan and Oaxaca spectra were computed from only 2 and 3 short-period SRO records, respectively; the Playa Azul spectrum was computed from 7 short-period SRO and DWWSSN records. The Michoacan spectrum and the Sept. 21 aftershock spectrum were computed from 15 GDSN records, mostly broadband. The spectral values at the low frequency end of the spectra in Figure 3 were obtained from the scalar seismic moments determined from long-period waves. Theoretical spectra for an $\omega^{-2}$ source model with a stress drop of 30 bars are shown as a reference (for a description of the model, see Houston and Kanamori [1986]). The dashed line shows the average source spectrum for 7 large interplate subduction earthquakes; we scaled the average spectrum to $\mathrm{M}_{\mathrm{W}}=8.0$ so that it could be easily compared to the Michoacan spectrum. Included in the average are the 1985 Michoacan, 1985 Válparaiso, Chile, 1983 Akita-Oki,
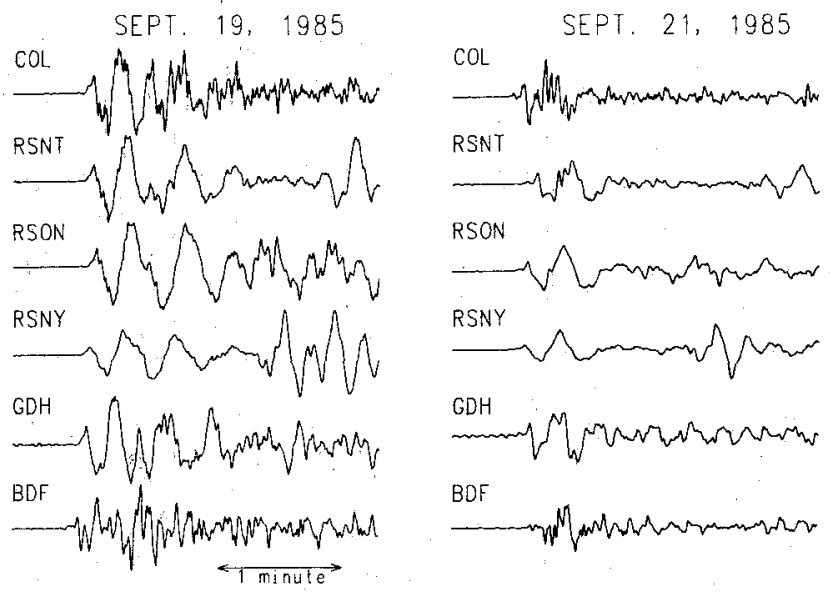

Fig. 2. Vertical components of teleseismic broadband GDSN records from stations $\mathrm{COL}$ (distance $=55^{\circ}$, azimuth $=338^{\circ}$ ), RSNT (45, 352), RSON (33, 10), RSNY (35, 36), GDH (59, $18)$, and BDF $(64,118)$. At each station, the mainshock and aftershock records are plotted to the same scale.
1983 Costa Rica, 1983 North Chile, 1982 Tonga, and 1980 Santa Cruz earthquakes. Relative to the average source spectrum, the spectrum of the Michoacan event is enriched at 30 $\mathrm{s}$ and depleted at 1 to $10 \mathrm{~s}$. This observation suggests that the high accelerations in Mexico City are not a source effect. The spectra of the Sept. 21 aftershock, 1981 Playa Azul, 1979 Petatlan, and 1978 Oaxaca events follow a trend similar to that of the Michoacan event. This spectral character may be typical of earthquakes in the Mexican subduction zone.

\section{Source Time Functions}

We performed a least-squares inversion of the broadband records of the Michoacan earthquake and its Sept. 21 aftershock to obtain the source time functions using the method of Hartzell and Heaton [1985]. In this method, a finite fault is approximated by a sum of point sources distributed over the depth range of the fault. We used three sources at 10,20 , and $30 \mathrm{~km}$ depth. For each depth $\mathrm{k}$, we computed a Green's function $\mathrm{G}_{\mathbf{k}}(\mathrm{t})$ by convolving the sum of delta functions representing the depth phases $(\mathrm{P}+\mathrm{pP}+\mathrm{sP})$ with the instrument response. The timing and amplitudes of
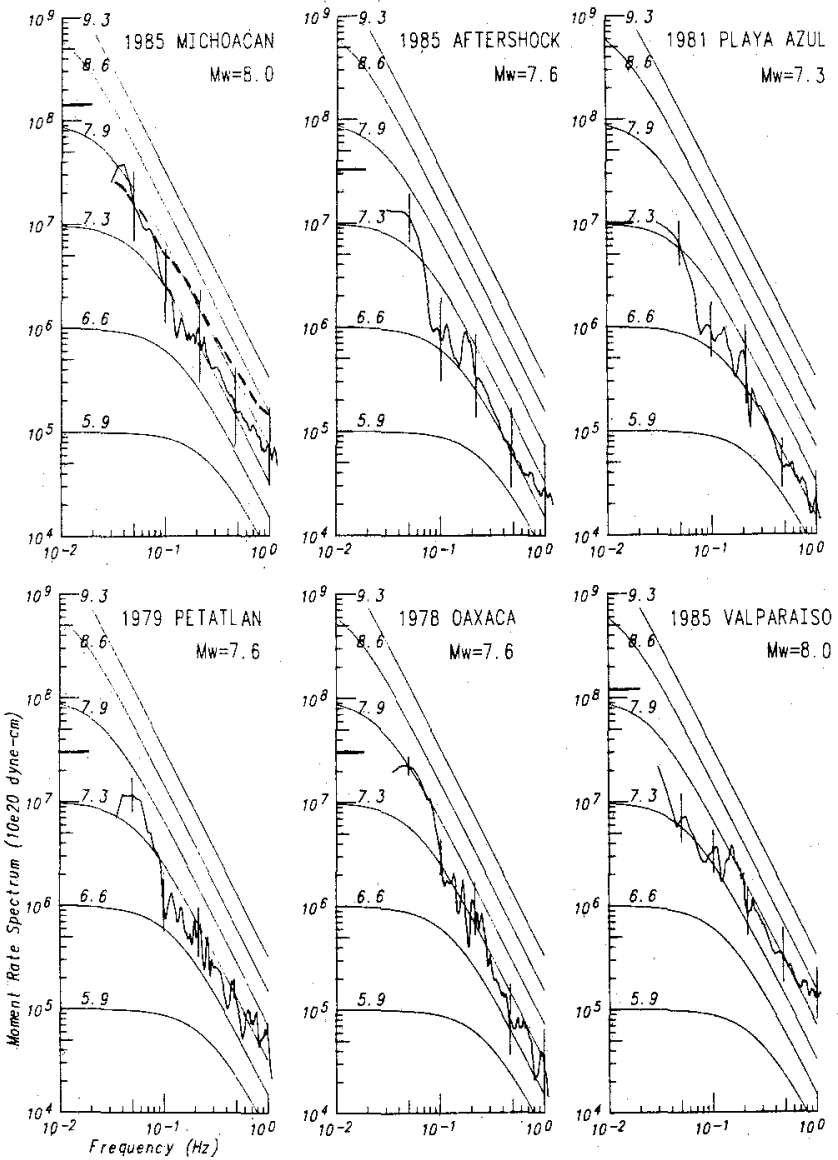

Fig. 3. Comparison of the average moment rate spectra for six earthquakes. The spectral values at the low frequency end were obtained from the scalar seismic moment determined from long-period waves. The vertical bars show standard deviations at selected frequencies. As a reference, theoretical spectra for an $\omega^{-2}$ model are shown by thin lines. The dashed line on the Michoacan spectrum shows the average spectrum of 7 subduction earthquakes scaled to $\mathrm{M}_{\mathrm{W}}=8.0$. The spectra of earthquakes along the Mexican trench are depleted in periods of 1 to $10 \mathrm{~s}$ relative to the average spectrum of subduction earthquakes. 


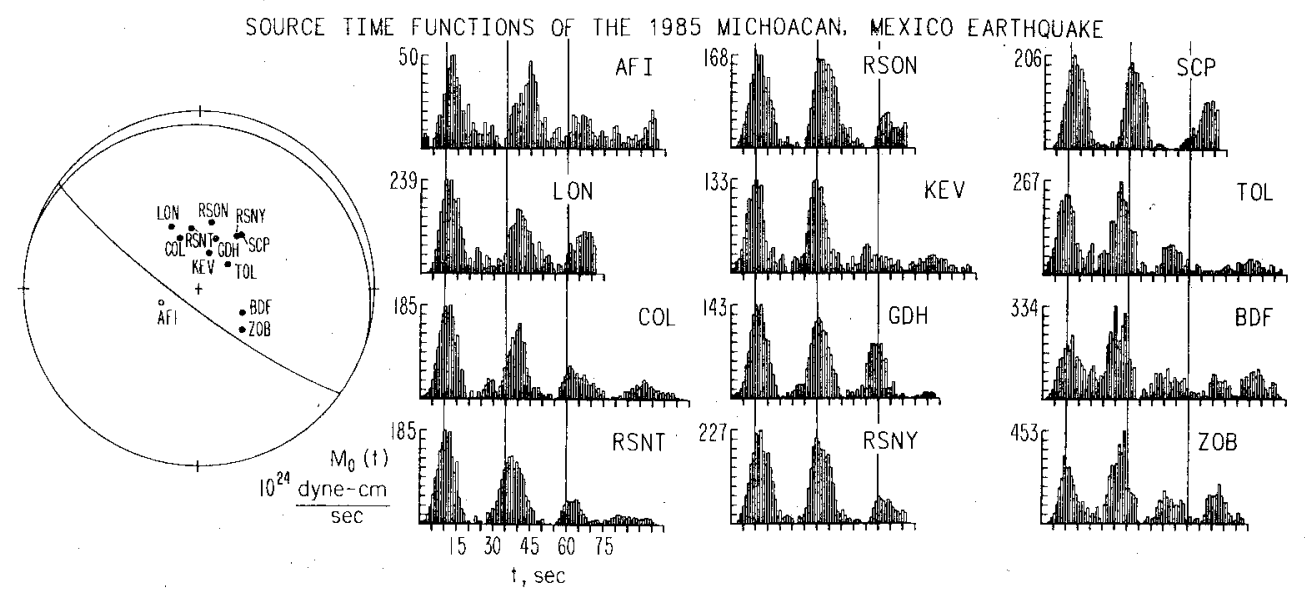

Fig. 4. Source time functions for the 1985 Michoacan earthquake obtained from broadband records. The focal mechanism and stations used in the inversions are shown. Directivity is evident in the timing between the first and second source pulses.

the depth phases depend on the focal mechanism and the velocity structure above the source; we used the focal mechanism given above and used a halfspace with a $\mathrm{P}$ velocity of $6.4 \mathrm{~km} / \mathrm{s}$ and an S-velocity of $3.5 \mathrm{~km} / \mathrm{s}$. If $\mathrm{F}_{\mathrm{k}}(\mathrm{t})$ is the teleseismic time function for the $\mathrm{k}^{\text {th }}$ depth, then the time function of the entire earthquake is $\sum_{k} F_{k}(t) . F_{k}(t)$ is determined by matching $\sum_{\mathrm{k}} \mathrm{F}_{\mathrm{k}}(\mathrm{t}) * \mathrm{G}_{\mathrm{k}}(\mathrm{t})$ to the observed seismogram using the method of least squares, while constraining $\mathrm{F}_{\mathrm{k}}(\mathrm{t})$ to be positive.

Figure 4 shows time functions determined from 12 broadband GDSN records. The records are of much higher quality than those used in previous modeling studies and are filtered to retain all frequencies lower than $1 \mathrm{~Hz}$. The beginning of each time function corresponds to $1 \mathrm{~s}$ before JB time. For the SRO station ZOB, we deconvolved the short-period SRO response and convolved in the broadband DWWSSN response. To obtain a good match to the other time functions, however, we had to reverse its polarity. Although ZOB is located close to the nodal line, the apparent polarity reversal is probably not due to a change in the mechanism during faulting. We could not match the unreversed record with changes in the mechanism within the range of uncertainty. The ZOB time function is, therefore, considered tentative.

Three source pulses are evident in Figure 4. We interpret these to be events on the fault plane. The first two source pulses are similar in moment and time width $(15 \mathrm{~s})$, and occur about $25 \mathrm{~s}$ apart. The existence of two such events is consistent with the near-field strong motions [Anderson et al., 1986]. The phase PP obscures part of the third pulse on the closest stations (LON, RSON, and SCP), but it can be clearly seen on RSNT and GDH. It contains only $20 \%$ of the moment of the first pulse, and occurs about $50 \mathrm{~s}$ after the first. A third event cannot be seen clearly on the strong motions. The moment determined from these broadband records averages about $30 \%$ of the total moment determined from 256 s surface waves.

We also inverted several records of the Sept. 21 aftershock for a source time function, using the same focal mechanism that we used for the mainshock. The aftershock time function consists of a $15 \mathrm{~s}$ wide pulse, similar to one of the mainshock pulses.

The mainshock time functions in Figure 4 clearly show directivity; the two large pulses are separated by $30 \mathrm{~s}$ for the northwestern stations (COL, LON, AFI) and by $20 \mathrm{~s}$ for the southern stations (BDF, ZOB). At each station we measured the time differences between the three pulses, and performed a least-squares nonlinear estimation to determine the strike, distance, and time (at the source) between them. The locations thus obtained are shown in Figure 1, where we arbitrarily located the first event at the earthquake's epicenter and ignored the dip of the slab. The shaded areas on Figure 1 show the inferred rupture zones of the three events, assuming a rupture velocity of $2.5 \mathrm{~km} / \mathrm{s}$ and event rise times of 10 $\mathrm{s}, 10 \mathrm{~s}$, and $7 \mathrm{~s}$. The second event occurs $26 \pm 0.4 \mathrm{~s}$ after the first, and $82 \pm 7.5 \mathrm{~km}$ southeastward of it. The apparent rupture velocity from the first to the second event is then 3.2 $\mathrm{km} / \mathrm{s}$. The relative location of the third source event is less well-constrained; the third pulse might represent simultaneous radiation from two or more parts of the fault plane. If it represents just one event, the third event occurs $47 \pm 1.0 \mathrm{~s}$ after the first, and about 35 to $50 \mathrm{~km}$ seaward of the second. Rupture velocities between the first and third or second and third events are about $2.5 \mathrm{~km} / \mathrm{s}$.

\section{Discussion}

Large subduction earthquakes along the Mexican trench usually consist of one simple source on time-scales longer than $10 \mathrm{~s}$ [Chael and Stewart, 1982; Astiz and Kanamori, 1984; Singh et al., 1984]. The Michoacan earthquake is composed mainly of two simple sources separated by about 80

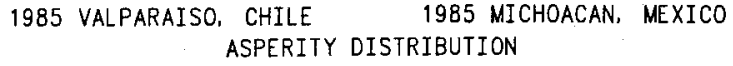
ASPERITY DISTRIBUTION
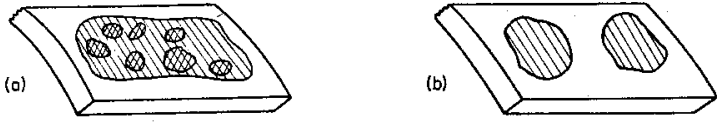

SOURCE TIME FUNCTIONS
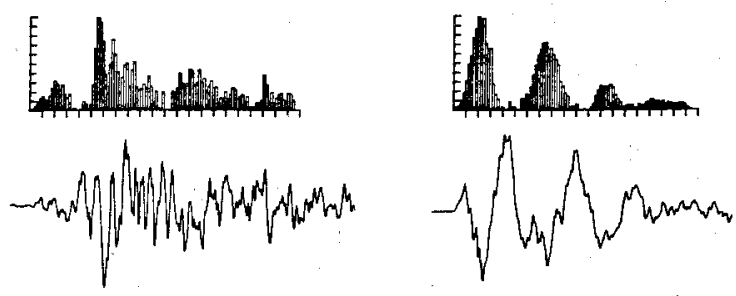

Fig. 5. Schematic comparison of records and time functions at the station RSNT, and inferred asperity distributions for (a) the 1985 Valparaiso, Chile earthquake and (b) the 1985 Michoacan, Mexico earthquake. 
$\mathrm{km}$. Most of the moment release (eg. displacement) came first from a region northwest of the rupture zone of the 1981 Playa Azul earthquake, and then $26 \mathrm{~s}$ later from a region southeast of that zone. The rupture zone of the 1981 Playa Azul earthquake, therefore, can be interpreted as a previously failed asperity that had not been loaded much since failure. Perhaps the rupture propagated from the first to the second source with relatively high velocity $3.2 \mathrm{~km} / \mathrm{s}$, because it did little or no work rebreaking the 1981 rupture zone. The Sept. 21 aftershock extended the rupture further south.

In order to compare the two largest earthquakes of 1985 , we analyzed GDSN records of the March 3, 1985 Valparaiso, Chile earthquake $\left(\mathrm{M}_{\mathrm{W}}=8.0\right)$ along the Chile trench. The Valparaiso earthquake's moment rate spectrum and a representative source time function are shown in Figures 3 and 5 , respectively. The Michoacan records, spectrum, and time functions contain less high frequency radiation than those of the 1985 Valparaiso, Chile earthquake. As shown schematically in Figure 5 , the Michoacan earthquake ruptured two relatively smooth, strong patches which generated large $30 \mathrm{~s}$ waves, but small 1 to $10 \mathrm{~s}$ waves. This behavior contrasts with that of the Valparaiso event which had a more complex rupture process and generated more 1 to $5 \mathrm{~s}$ energy. These differences between the two earthquakes discerned from teleseismic records can also be seen in the near-field strong motions. For a given distance, except at Mexico City, the near-field peak accelerations are significantly higher for the Valparaiso earthquake than for the Michoacan earthquake [Anderson et al., 1986]. Admittedly, most of the peak accelerations occur at frequencies greater than $1 \mathrm{~Hz}$ (except at Mexico City). Also, the Mexican accelerographs are generally sited on hard rock (except at Mexico City), while some of the Chilean instruments are not [Anderson et al., 1986]. Nevertheless, the large systematic difference suggests that the anomalously high accelerations in Mexico City are not a source effect. This conclusion is consistent with the teleseismic source spectra of the two earthquakes.

From Figure 3 a relative lack of high frequencies appears to characterize earthquakes along the Mexican trench, if recent large events are typical. This spectral character, which implies relative smoothness at scale-lengths of 3 to $30 \mathrm{~km}$, may be typical of the Mexican subduction zone. This is also consistent with the relative lack of aftershocks of Mexican subduction earthquakes [Singh and Suarez, 1985]. The cause must lie in the nature of the interplate coupling, which may reflect a relative lack of relief on the seafloor or conditions at the subduction thrust interface, such as subduction of sediments or high pore pressure.

\section{Conclusions}

The Michoacan earthquake source spectrum is enriched at $30 \mathrm{~s}$ and depleted at 1 to $10 \mathrm{~s}$ relative to the average source spectrum of large interplate subduction events. Source spectra for the Sept. 21 aftershock, 1981 Playa Azul, 1979 Petatlan, and 1978 Oaxaca events follow a trend similar to that of the 1985 Michoacan event. This spectral character, which implies relative smoothness at scale-lengths of 3 to 30 $\mathrm{km}$, may be typical of the Mexican subduction zone.

A station by station least-squares inversion for the source time function of the Michoacan earthquake yields three source pulses. The first two are similar in moment and occur
$26 \mathrm{~s}$ apart. The variation from station to station of their separation in time indicates that a second source event originated about $80 \mathrm{~km}$ to the southeast of the first, implying southeastward rupture along the trench. The third pulse contains only $20 \%$ of the moment of the first.

The mainshock records, spectrum; and time functions contain less high frequency radiation than those of the 1985 Valparaiso, Chile earthquake. The Michoacan earthquake ruptured two relatively smooth, strong patches which generated large $30 \mathrm{~s}$ waves, but small 1 to $10 \mathrm{~s}$ waves. This behavior contrasts with the 1985 Valparaiso event which had a more complex rupture process and generated more 1 to $5 \mathrm{~s}$ energy. Consistent with this are the higher near-field accelerations recorded during the Valparaiso earthquake compared to the lower accelerations generated by the Michoacan earthquake (except at Mexico City). The striking consistency of the near-field and teleseismic data for the Michoacan and Valparaiso earthquakes shows that broadband teleseismic data are useful in characterizing strong motions from large and great earthquakes.

This study indicates that the relatively high accelerations in Mexico City were not a source effect, that is, were not due to an unusually intense source (for $\mathrm{M}_{\mathrm{W}}=8.0$ ); however, the extended duration of shaking due to the multiple sources was responsible for much of the damage.

Acknowledgements. Steve Hartzell helped us use his program to invert for source time functions. John Vidale and an anonymous reviewer helped improve the manuscript. This research was supported by U.S.G.S. Grant 14-08-0001-G1170. Contribution No. 4312, Division of Geological and Planetary Sciences, California Institute of Technology.

\section{References}

Anderson, J. G., P. Bodin, J. N. Brune, J. Prince, and S. K. Singh, Strong ground motion and source mechanism of the Mexico earthquake of September 19, $1985\left(\mathrm{M}_{\mathrm{S}}=8.1\right)$, Science, in press, 1986.

Astiz, L., and H. Kanamori, An earthquake doublet in Ometepec, Guerrero, Mexico, Phys. Earth Planet. Interiors, 34, 24-45, 1984.

Chael, E., and G. Stewart, Recent large earthquakes along the Middle American trench and their implications for the subduction process, J. Geophys. Res., 87, 329-338, 1982.

Hartzell, S. H., and T. H. Heaton, Teleseismic time functions for large, shallow subduction zone earthquakes, Bull. Seism. Soc. Am., 75, 965-1004, 1985.

Houston, H., and H. Kanamori, Source spectra of great earthquakes: teleseismic constraints on rupture process and strong motion, Bull. Seism. Soc. Am., 76, 19-42, 1986.

Singh, S. K., T. Dominguez, R. Castro, and M. Rodriguez, P-waveform of large, shallow earthquakes along the Mexican subduction zone, Bull. Seism. Soc. Am., 74, 2135-2156, 1984.

Singh, S. K., and G. Suarez, Regional variations in the number of aftershocks of large subduction zone earthquakes (abstract), EOS, 66, 958, 1985.

(Received February 24, 1986; accepted April 16, 1986.) 